\title{
Pharmaceutical Engineering Design based on professional design competition and comprehensive project
}

\author{
Zhenhua Chen ${ }^{1}$, Yuyu Xü,a, Leilei Zhou ${ }^{1}$, Ying Yin ${ }^{1}$ and Xuemin Duan ${ }^{1}$ \\ ${ }^{1}$ School of Pharmacy, Jiangxi Science and Technology Normal University, Nanchang 330013, China \\ ${ }^{2}$ Faculty of Tourism, Jiangxi Science and Technology Normal University, Nanchang 330022, China
}

Keywords: pharmaceutical engineering; design competition; comprehensive project; GMP; public works

\begin{abstract}
Objective: To improve the capabilities of solving practical engineering problems for Pharmaceutical engineers. Methods: All subjects were divided into two groups, and in the experimental group, elements of professional design competition and plant design with preparation technology, equipment, GMP and public works were introduced into the Pharmaceutical Engineering design. Results: The experimental group had high enthusiasm with strong motivation, deep and detailed communication and discussion, also created a better designed works. Conclusion: The method used in this paper can improve the engineering design capabilities.
\end{abstract}

\section{Introduction}

Pharmaceutical Engineering major needs to train engineering and technical personnel for pharmaceutical enterprises and curriculum design is one of the main practical courses to develop students' engineering calculation and design capabilities. The course is generally carried out in senior, and is a usage and consolidation of comprehensive knowledge after students finished all professional core curriculums. The curriculum design topics are more from the classic knowledge unit and there are few excellent courses or high quality resource sharing course for Pharmaceutical Engineering Curriculum Design Course in Chinese universities. Therefore, the level of the curriculum design course in different universities differs a lot. Especially in non-Engineering Colleges, teaching quality of the curriculum design course is unsatisfactory.

By visiting JZJT, Huiren Group, Salubris and other large pharmaceutical companies inside and outside Jiangxi province, we found that the main expectations of pharmaceutical companies for the pharmaceutical engineering graduates are focused on solving engineering problems in the production process. Thus, the engineering capabilities are essential for the students and their future career.

The Education Department of higher education of the College of pharmacy professional teaching and guidance committee (now the Pharmacy Professional Teaching Guidance Committee) organized a national pharmaceutical engineering design competition starting in 2011 , once a year. In order to improve students' pharmaceutical engineering design concept and capacity, promote the reform of teaching engineering design courses and guide colleges and universities to strengthen the cultivation

${ }^{a}$ Corresponding author : zhenhuadeai@163.com 
of students' engineering design capabilities. The competition topics are often from factories and Pharmaceutical Industry Design Institute.

The project introduces useful elements of national pharmaceutical engineering design competition into the Pharmaceutical Engineering Curriculum Design Course, which orients the subject competition and explores teaching reform for curriculum design, improving the quality of teaching curriculum and students' design interests in learning curriculum design and enhancing engineering capabilities of students.

\section{The reform of teaching content}

The curriculum design topics used to be from the classic knowledge unit, such as a design of tablet workshop, the design of capsule workshop, the design of injection production workshop and raw material drug production workshop and so on. Design files are rarely associated with the actual production and usually abstract and empty.

By studying the competition topics of the National Pharmaceutical Engineering Design Contest over the years, the author found that topics were often from a specific production practice, putting engineering projects as the main line and closing to the latest technology and the requirements of industry. For example, in 2011, the engineering design of the intravenous Omeprazole sodium sterile lyophilized preparation workshop introduced isolators, RABS and other latest technology. In 2012, the design of peptide lyophilized injectable formulation production line from a new pharmaceutical project, regarded requisite file of the owner as topic. In 2013, the design of multiple lyophilized preparation workshop required giving consideration of the demand of production expansion in future because of the approval and marketing of new products. In 2014, the design of chemical raw materials versatile workshop needed to manufacture products of three different chemical raw materials and diversify production shift.

The assignment files of Design Contest provided direction for the reform of teaching content in the pharmaceutical engineering curriculum design. We referred to the topics and requirements of design competition of calendar year and constantly enrich and update the curriculum design exams, making topics more vivid and true. At the same time the teaching content is gradually proximate the latest technology requirements of the pharmaceutical companies. So students can be able to come into contact with front-line industry dynamics in the classroom.

\section{Reform of teaching methods}

The traditional curriculum design is often a grouped in the bedroom as a unit or arbitrarily assigned according to student number by the teacher. Each group has a design task, guided by a teacher, to complete the design specification in time. The design process does not specify a fixed place and students usually contact with teachers through QQ, telephone or to the office to find the instructor doubts after they encounter problems.

After the introduction of the design competition into teaching of curriculum design, students can sign up autonomously and participating students form a team according to their interests, strengths and so on, which forms a group of curriculum design. In this group, you can see more autonomy in students, better teamwork, excellent coordination, significant increase of the students' interests and enthusiasm. Meanwhile, according to the discipline of design competition, each team is arranged two teachers to guide them. Profession and advantages of different instructor, complement each other. Students can get a more comprehensive professional guidance. Third, students are required to gather together at a predetermined network place to design, so as to help the teachers' centralized guidance and management and teaching efficiency and quality will get promoted. Finally, the design topic instructor themselves for the first time to encounter is relatively novel, so the design process is the only student-centered. Seminar discussions can be conducted under the guidance of teachers' participation and members can discuss with each other about solving solutions, which forms a research-mutual learning, so students' learning and analytical ability will obtain a further improvement. 


\section{Reform of assessment methods}

Assessment program is an important way to test students' mastery of this course and to examine teaching effectiveness of teachers. Therefore, evaluation methods and scoring criteria in science curriculum have a very important significance for enhancing the quality of teaching.

Pharmaceutical engineering design competition usually consists of preliminary and final. Preliminaries' assessments base mainly on the design specification and its scoring project includes five contents: the project management, analysis of production and operation, analysis of process equipment and equipment selection, analysis of facility layout and design of documenting. The final assessments are based on the reply, its scoring project includes two contents: the design of statements and production of presentation materials and live content ratings reply. They both have detailed scoring criteria.

Referring to pharmaceutical engineering as a model of design competition, we revised examine methods for pharmaceutical engineering curriculum design, consisting of usual results (discussion process), the design specification and the reply. Each section sets a detailed scoring criteria. Meanwhile, referring to the mode of design competition, we changed the way only by an instructor scoring into a team of 3-5-member, adding seriousness, objectivity and impartiality to the course examination and it allows students to gain further correct attitude towards learning.

\section{Manufacturing animation and video clips}

At the reply stage of pharmaceutical engineering design competition, all teams usually show their design work by making a flash animation. These excellent flash animations become an excellent teaching material of Course Design. Of course, it is not enough to rely solely on the students' works, the author also develops independently some pharmaceutical equipment and workshop process layout animation according to the needs of teaching. In addition, the author films and produces a number of video materials by participating in teacher training of pharmaceutical engineering design competition Organizing Committee, National Pharmaceutical Machinery Exhibition twice a year and visiting to pharmaceutical companies.

Making these vivid animation and audio-visual materials, has enriched teaching materials of curriculum design and made students more intuitive understanding of the productive process of drugs, operational principle of equipment and requirements of workshop layout in pharmaceutical industry. So the originally boring, difficult understanding of engineering knowledge become life and easy to understand. It not only reduces the difficulty on teaching, but also improves the teaching effectiveness.

\section{Summary and Outlook}

The project introduces beneficial elements of National Pharmaceutical Engineering Design Competition into the teaching of Curriculum Design Course for Pharmaceutical Engineering major. By comparison we found that: the students were little enthusiastic about learning with weak initiation and poor quality of design specifications under the traditional teaching methods of this course ; While students in the experimental group had high enthusiasm with strong motivation, obviously deep and detailed communication and discussion with the instructor. The high class design specification under the mode for design competition and these make them get better grades. These students were recommended to participate the National Pharmaceutical Engineering Design Competition and all also have achieved good grades, they won second prize for two consecutive years in the National Pharmaceutical Engineering Students Design Competition in 2013 and 2014. What's more, we found that these students generally feel a huge harvest in learning this course, and it also a great help to their work through their return visits.

Meanwhile, the instructor of the course has significantly improved their engineering design capability and teaching level of professional courses by participating teacher training of the National 
Design Competition and exchanging ideas with other industry experts and university teachers in the country.

In the future, we will promote this teaching achievement in pharmaceutical engineering curriculum design, arrange all the students with grouping and lay out of assignment file, guide and examine courses according to the mode for design competition, making more students benefit from it. Of course, teaching methods are without fixed way and many teaching methods can be used in Pharmaceutical Engineering Curriculum Design. Whichever method, it's good or bad depending on whether it reaches the teaching purposes. In terms of professional orientation for training applied talents as the goal, the success or failure of our teaching reform should rely on whether the students' engineering practice capability has been improved. So, in the future work of students, we need track their working ability and feedback from the enterprise, so as to perfect, popularize and apply the achievement of the teaching reform.

Acknowledgments This work was supported by a grant from the Research Project on Teaching Reform of Jiangxi Province (JXJG-14-10-22).

\section{References}

1. Hang Song, Hen Zhang, Risheng Yao, and etc: Higher Education in Chemical Engineering Vol. 131 (2013), p. 1

2. Xizhong Cai: Chemical Vocational and Technical Education Vol. 2 (2007), p. 3

3. Dongju Zhou, Yanping Zhang, and Junying Ma: Journal of Jiamusi Education Institute Vol. 102 (2010), p. 238

4. Pei Wang, Yiping Chen, Jing $\mathrm{Xu}$, etc: Journal of Changchun University of Traditional Chinese Medicine Vol. 25 (2009), p. 810

5. Hang Song, in: Introduction to pharmaceutical engineering technology, edtied by Chemical Industry Press, Beijing, CN (2013), in press.

6. Hongbin Zhang, in: Engineering technology and equipment for pharmaceutical preparation, edtied by Chemical Industry Press, Beijing, CN (2009), in press.

7. WU Jing-jing, DAI Yu-gong, ZHANG Hua, etc: Guangzhou Chemical Industry Vol. 42 (2014), p. 204

8. Lu Wenyu, Yuan Yingjin, Zhu Hongji, and etc: Higher Education in Chemical Engineering Vol. 125 (2012), p. 28

9. FENG Gui-peng: Guangzhou Chemical Industry Vol. 43 (2015), p. 283

10. Yi Xuewen: Science and Technology Innovation Herald Vol. 29 (2013), p. 255 